\title{
Cloning, Expression, Purification and Characterization of UL24 Partial Protein of Duck Enteritis Virus
}

\author{
Renyong Jia Anchun Cheng Mingshu Wang Dekang Zhu \\ Han Ge Hongyi Xin Fei Liu Qihui Luo Yufei Guo Xuefeng Qi \\ Zhongqiong Yin Xiaoyue Chen \\ Avian Disease Research Center, College of Veterinary Medicine of Sichuan Agricultural University, Ya'an, China
}

\section{Key Words}

Duck viral enteritis · Duck enteritis virus • UL24 partial

protein $\cdot$ Prokaryotic expression

\begin{abstract}
The UL24 gene of duck enteritis virus (DEV) is conserved across herpesviruses, but its protein characterization has not been reported. We expressed the UL24 gene in Escherichia coli BL21 from a recombinant plasmid pET32a/DEV-UL24 and used the resulting protein to raise antiserum. This antiserum recognized a 38-kDa protein in lysates from infected cells. SDS-PAGE analysis showed that the UL24 partial protein was highly expressed after induction by 0.4 mM IPTG at $30^{\circ}$ for $6 \mathrm{~h}$. The results of purification revealed that expression protein was more purified using the method of electrophoresis than that of chromatography, but the yield was lower. In immunogenicity analysis, the protein could significantly elicit a specific antibody response in immunized ducklings when compared with the control groups, and the titers against expression protein reached the peak 1:5,120 $\left(\mathrm{OD}_{450 \mathrm{~nm}}=2.5\right)$ on day 28 after immunization, while with mean titers of 1:10,240 $\left(O D_{450 \mathrm{~nm}}=3.37\right)$ in DEV commercial attenuated vaccine strain immunized duckling groups. It showed that expression protein is immunogenic in laboratory ducklings. On the basis of subcellular location, UL24 ap-
\end{abstract}

peared to be predominantly nuclear membrane-associated, especially at later times in infection, and provided a good tool to further study the biofunctions of UL24 protein.

Copyright $\odot 2009$ S. Karger AG, Basel

\section{Introduction}

Herpesviridae encompass a diverse family of animal viruses that possess a large linear double-stranded DNA genome (120 up to $230 \mathrm{~kb}$ ) [1]. The genome contains a lot of different genes, including one known as UL24. UL24 is evolutionarily conserved among many herpesviruses and is considered to be a core herpesvirus gene [2]. This conservation suggests an important role for UL24 in the life cycle of these viruses, but little is known about its properties or function at present. Analysis of the role of the UL24 gene in vitro and in vivo has been complicated by the fact that certain mutations in UL24 can affect the expression of the overlapping UL23 (TK) gene [3]. Indeed, UL24 null mutations or mutations in the conserved regions of UL24 result in decreased viral yields in cultured cells [4]. Herpes simplex virus 2 (HSV-2) UL24 gene

\section{R.J., A.C., M.W. and D.Z. contributed equally to this work.}

\section{KARGER}

Fax +41613061234 E-Mail karger@karger.ch www.karger.com
(C) 2009 S. Karger AG, Basel

0300-5526/09/0526-0326\$26.00/0

Accessible online at:

www.karger.com/int
Anchun Cheng

Avian Disease Research Center

College of Veterinary Medicine of Sichuan Agricultural University

Ya'an 625014 (China)

Tel./Fax +86 835288 5774, E-Mail chenganchun@vip.163.com 
product is identified as a minor virion component, probably a tegument protein, with a molecular mass of $32 \mathrm{kDa}$ which is expressed late in infection [5]. Jacobson et al. [6] reported that mutations in UL24, in mice, cause especially severe defects in viral replication and reactivation from sensory ganglia. Human herpes virus 6 (HHV-6) UL24, and HHV-7 UL24 lack an N-terminal signal sequence and may represent a glycoprotein exon [7]. HSV-1 UL24 gene product was shown to be a nucleus-associated protein [8] that is not required for growth in cultured cells [6]. Deletion of the bovine herpesvirus type 1 (BHV1) UL24 open reading frame had little effect on viral replication in vitro [9]. Although the syncytial phenotype observed in some UL24 mutant viruses has led to the suggestion that UL24 may encode a membrane protein [10, 11], there has been no definitive evidence to support this hypothesis [8]. DNA sequence analysis has revealed that UL24 homologs are present throughout the Herpesviridae family.

Duck virus enteritis (DVE), which is caused by duck enteritis virus (DEV), a member of the Herpesviridae family, is an acute and contagious herpesvirus infection of waterfowls such as ducks, geese and swans with high morbidity and mortality [12-17]. Most of the previous research work has focused on the epidemiology and prevention of this disease. However, the molecular biology information about the DEV genome is limited. Recently, the UL24 gene was isolated and identified from DEV $\mathrm{CHv}$ strain in our laboratory by the methods of two-dimensional gel electrophoresis, Western blot, liquid chromatography-electrospray ionization-tandem mass spectrometry (LC-ESI-MS/MS), PCR, sequencing, and Southern blot. Up to now, there is little literature about DEV UL24 gene. So in an effort to elucidate the properties and function of this novel gene, we present here its cloning, expression, purification and characterization.

\section{Materials and Methods}

\section{Materials}

Duck enteritis virus CHv strain was provided by the Key Laboratory of Animal Disease and Human Health of Sichuan Province, and propagated in duck embryo fibroblasts (DEFs). The expression vector $\mathrm{pET} 32 \mathrm{a}(+)$ and its host strain Escherichia coli BL21 (DE3) were purchased from Novagen. Restriction enzymes, EcoRI and XhoI, STAR HS DNA polymerase, T4 DNA ligase, dNTPs, and pMD-18T vector were purchases from TaKaRa Biotechnology Co. Ltd. Primers were synthesized at TaKaRa (Dalian, China). Small-scale preparation of plasmid DNA kit and gel extraction kit purification were from Tiangen Biotechnology Co. Ltd. Horseradish peroxidase (HRP)-conjugated goat anti-rabbit IgG was from Beijing Zhongshan Co. Ltd. HRP-conjugated goat anti-duck IgG was from KPL Co. Ltd. All other chemicals were from Sigma, Promega, or Bio-Rad Co. Ltd.

Culture and Nuclear DNA Isolation from DEV CHv Strain

DEFs were propagated in Dulbecco's minimal essential medium (DMEM) (Gibco-BRL) supplemented with 10\% fetal bovine serum (FBS) (Gibco-BRL) at $37^{\circ}$, and then infected by DEV. Virus was grown in DMEM medium supplemented with 2-3\% FBS, collected at $48 \mathrm{~h}$ post incubation. DNA extraction from DEV was carried out using plasmid DNA kit following the manufacturer's instructions.

Primer Design and PCR Amplification of the UL24 Gene

The nucleotide sequence coding for UL24 protein of DEV was obtained and identified from the isolated viral proteins to viral genes in our laboratory. After the antigenic determinant of the UL24 protein was analyzed using the method of Kolaskar et al. [18] (http://immunax.dfci.harvard.edu/Tools/antigenic.pl), amino acids 241-410 were identified as being a major species-specific epitope. To amplify the gene with the region coding antigenic determinant, the primers for the PCR were designed to contain EcoRI and XhoI restriction sites (underlined) at the $5^{\prime}$ end of sense primer and anti-sense primer, respectively. 5'-GAA TTC ATA CCT ACC AAA GGT AAG CGC-3', R 5'-CTC GAG CTA GTG TTT AGT TGG TCT GAA-3'. PCR conditions consisted of $1.0 \mu \mathrm{l}(50 \mathrm{ng} / \mu \mathrm{l}) \mathrm{DNA}$ and $2 \mu \mathrm{l}$ of each primer $(25 \mathrm{pM})$ in a $10 \mu \mathrm{l}$ of $\times 5$ primeSTAR buffer, $4 \mu$ l of $10 \mathrm{mM}$ dNTP $(2.5 \mathrm{~mm}$ each $)$ mixture and $0.5 \mu$ l of primer STAR HS DNA polymerase in a final reaction volume of $50 \mu$ l on Biometra PCR equipment (Germany). PCR was initiated with an incubation step at $98^{\circ}$ for $5 \mathrm{~min}$, followed by 30 cycles of denaturation at $95^{\circ}$ for $40 \mathrm{~s}$, annealing for $45 \mathrm{~s}$ at $54^{\circ}$, and extension at $72^{\circ}$ for $40 \mathrm{~s}$, then with a final extension step at $72^{\circ}$ for $10 \mathrm{~min}$. The amplified DNA products were electrophoresed on a $1.0 \%(\mathrm{w} / \mathrm{v})$ agarose gel, and analyzed using gel imaging system (Bio-Rad, USA).

\section{Cloning and Identification of the UL24 Gene}

The PCR amplified product of the UL24 gene was purified by the Gel Extraction kit according to the manufacturer's instructions. After digestion with EcoRI and XhoI, the purified DNA fragment was inserted into $\mathrm{pMD}-18 \mathrm{~T}$ vector which is an AT cloning vector, and confirmed by restricted enzymes analysis and sequencing. The correct recombinant vector was named as pMD18/DEV-UL24. Subsequently, the constructed pMD-18/DEVUL24 was cut with EcoRI and XhoI and the insert was subcloned into pET32a $(+)$ expression vector precut with the same enzymes. Competent $E$. coli DH5 $\alpha$ cells were transformed with the ligation product. Cells were cultured overnight at $37^{\circ}$ in Luria-Bertani broth plates containing $100 \mu \mathrm{g} / \mathrm{ml}$ ampicillin. The colonies were individually stored at $-70^{\circ}$. The subclones were verified to be sure no errors were made by restriction analysis, E. coli BL21 (DE3) cells were transformed with positive recombinant plasmid and used for protein expression.

\section{Expression of Recombinant Protein and Isolation of Inclusion}

Bodies

Overnight grown cultures of recombinant subclones of UL24 gene were inoculated into Luria-Bertani broth containing ampicillin $(100 \mu \mathrm{g} / \mathrm{ml})$. To obtain as much fusion protein as possible, 
we optimized the condition for induction. Once an optical density at $600 \mathrm{~nm}\left(\mathrm{OD}_{600 \mathrm{~nm}}\right)$ of the cultures reached about 0.6 , the bacterial culture was induced with different concentrations of isopropyl- $\beta$-D-thiogalactopyranoside (IPTG) $(0.2-1.2 \mathrm{mM})$ or allowed to grow for $1-6 \mathrm{~h}$ at $20-37^{\circ}$. The cells were harvested by centrifugation at $4,000 \mathrm{~g}$ and $4^{\circ}$ for $10 \mathrm{~min}$. The total cell lysate was prepared by the addition of sample buffer [19] to the pellet followed by heating at $95^{\circ}$ for $5 \mathrm{~min}$. Total cell protein was analyzed by SDS-PAGE using 12\% polyacrylamide gel. Uninduced recombinant clone and $E$. coli host cells (with and without IPTG) were used as controls.

The induced cells were centrifuged at $4,000 \mathrm{~g}$ for $10 \mathrm{~min}$, washed 3 times in a washing buffer containing $20 \mathrm{mM}$ Tris- $\mathrm{HCl}$ $\mathrm{pH} 8.0$, and lysed in $30 \mathrm{ml}$ of washing buffer containing $1.0 \mathrm{mg} / \mathrm{ml}$ lysozyme at $-20^{\circ}$ overnight. The cell lysate was clarified by centrifugation at $27,000 \mathrm{~g}$ for $20 \mathrm{~min}$ at $4^{\circ}$ and the supernatant was discarded, after it was disrupted by an ultrasonic cell disrupter with pulses of $200 \mathrm{~W}$ at $4^{\circ}$ for $30 \mathrm{~s}$ intermittence 8 times. The pellets of the inclusion bodies were resuspended in $40 \mathrm{ml}$ cold washing buffer (20 mM Tris- $\mathrm{HCl}, 2 \%$ Triton X-100 (v/v), pH 9.0) under constant stirring for $15 \mathrm{~min}$, then followed by centrifugation at $10,000 \mathrm{~g}$ for $15 \mathrm{~min}$ at $4^{\circ}$, and the above steps repeated once. Finally, the pellets were washed twice in $20 \mathrm{~mm}$ Tris- $\mathrm{HCl}$ and $0.02 \mathrm{M} \mathrm{NaCl}(\mathrm{pH} 8.0)$, and solubilized in denaturing buffer $(8 \mathrm{M}$ urea, $100 \mathrm{mM} \mathrm{NaH}_{2} \mathrm{PO}_{4}, 10 \mathrm{mM}$ Tris- $\mathrm{HCl}, \mathrm{pH}$ 8.0) for $2 \mathrm{~h}$ at room temperature with occasional shaking. Solubilized proteins were separated from insoluble material by centrifugation at $27,000 \mathrm{~g}$ for $20 \mathrm{~min}$ at $4^{\circ}$, and purified by the following different methods.

\section{Comparison of Methods for the Recombinant Protein}

Purification

Purification of Protein Using Affinity Chromatography. An immobilized metal ion affinity chromatography column $(50 \mathrm{ml})$ was prepared by loading the Ni-NTA agarose on a column and equilibrating with 5 bed volumes equilibration buffer ( $8 \mathrm{M}$ urea, 500 $\mathrm{mM} \mathrm{NaH}_{2} \mathrm{PO}_{4}, 500 \mathrm{mM} \mathrm{NaCl}, \mathrm{pH}$ 7.4). Denatured soluble protein was loaded on the column and the Ni-NTA column was washed with $200 \mathrm{ml}$ equilibration buffer, followed by a second wash with $200 \mathrm{ml}$ equilibration buffer containing $20 \mathrm{mM}$ imidazole to remove any loosely bound protein. The histidine-tagged recombinant protein was eluted from the column by $200 \mathrm{ml}$ linear gradient equilibration buffer containing 20-250 mM imidazole, with protein purification system (Biologic Duo Flow, Bio-Rad, USA). Bound protein fractions were pooled, dialyzed, and concentrated to $1 / 10$ of its original volume by lyophilization [20], and the expression yield was analyzed by SDS-PAGE using the Quantity One quantitative software (Bio-Rad) according to the relative band intensities of Coomassie blue stain [21].

Purification of Protein Using SDS-PAGE. The 12\% SDS-PAGE gel was prepared in PROTEAN $\Pi$ xi Gel System (Bio-Rad, USA) with $2-\mathrm{DE}$ comb, the solubilized protein and protein marker were added to sample well and marker well, respectively, and separated by electrophoresis with $350 \mathrm{~V}$ at $16^{\circ}$. The recombinant protein band was cut from the gel according to the corresponding site of protein beforehand and put into a dialysis bag. The recombinant protein was eluted in SDS-running buffer $(25 \mathrm{mM}$ Tris, $250 \mathrm{mM}$ glycine, and $0.1 \%$ SDS) for $120 \mathrm{~min}$ at $70 \mathrm{~V}$ with horizontal electrophoretic apparatus. The protein in dialysis bag was pooled, dialyzed, and concentrated as description above.
SDS-PAGE and Western Blot Analysis

For the Western blot procedure of Towbin et al. [22], proteins separated on $12 \%$ SDS-PAGE gels were transferred to polyvinylidene difluoride membrane. The membrane was incubated with blocking buffer containing $5 \%$ bovine serum albumin (BSA) in TBS (50 mM Tris- $\mathrm{HCl}, 150 \mathrm{mM} \mathrm{NaCl}, \mathrm{pH} 7.5)$ for $1 \mathrm{~h}$ at room temperature. Serum of rabbit anti-DEV as primary antibodies were diluted at a ratio of 1:300 with blocking buffer and added to the membrane overnight at $4^{\circ}$. The membrane was washed 3 times for 10 min each with TBS containing 0.05\% Tween-20 (TBST) and incubated for $2 \mathrm{~h}$ with HRP-conjugated goat anti-rabbit IgG dilution of 1:500 in blocking buffer. Blots were again washed with TBST and developed with substrate solution $(0.05 \%$ diaminobenzidine in TBS, $0.1 \%$ hydrogen peroxide) for $2-5 \mathrm{~min}$ at room temperature. Finally, the reaction was stopped by the addition of distilled water to strips.

\section{Production of Polyclonal Antibodies against the Recombinant}

Protein

The purified denatured protein was done by gradient dialysis in $0.85 \% \mathrm{NaCl}$ solution containing $6,5,4,3,2 \mathrm{M}$ urea, and changed 3 times over 1 day at $4^{\circ}$ in each solution. Also, aggregation was removed by centrifugation and the supernatant was collected as soluble refolded protein. Five ducklings were immunized subcutaneously with the emulsified UL24-soluble refolded protein at $0.2 \mathrm{mg} /$ duckling 3 times consecutively at every week interval. The first dose was administered with Freund's complete adjuvant, which was mixed with the protein in a $1: 1$ ratio $(\mathrm{v} / \mathrm{v})$ and fully emulsified with brief sonication, while subsequent doses were given with Freund's incomplete adjuvant. Sera were obtained after the last bleeding. Antibody titers were determined by ELISA. The control groups were immunized with DEV commercial attenuated vaccine strain as positive group and sterile saline as negative group.

\section{Immunogenicity Analysis of UL24 Partial Protein}

The ELISA procedures were as follows: 96-well flat-bottom plates were coated with different dilutions of purified UL24 partial protein $(1: 2$ to $1: 3,200)$ overnight at $4^{\circ}$ and blocked with PBS containing $1 \%$ BSA for $1 \mathrm{~h}$ at room temperature. After three washings with PBS containing 0.05\% Tween-20 (PBST), the sera from immunizing ducklings were added at different dilutions (1:2 to $1: 3,200)$ to the wells and incubated for $2 \mathrm{~h}$ at room temperature. Finally, after being washed, plates were incubated with HRP-conjugated goat anti-duck IgG (KPL, USA). The antibody was removed, and the plates were washed 3 times with PBST. The reaction was developed with the 3,3,5,5-tetramethylbenzidine (TMB) substrate with $\mathrm{H}_{2} \mathrm{O}_{2}$. The optical density was measured at $450 \mathrm{~nm}$ using Bio-Rad 860 reader (Bio-Rad, USA) after stopping the reaction with $2 \mathrm{~mol} / \mathrm{l} \mathrm{H}_{2} \mathrm{SO}_{4}$.

\section{Subcellular Location of UL24 Protein}

DEFs were grown on glass coverslips and mock infected or infected with DEV-CHv at a multiplicity of infection of $1 \mathrm{PFU} /$ cell. After a 1-hour adsorption at $37^{\circ}$, maintenance medium supplemented with $2 \%$ FBS was added and the incubation was continued until 12, 24, and $48 \mathrm{~h}$ post infection, respectively. All of the subsequent manipulations were performed at room temperature. The coverslips were washed with PBS and harvested by fixation in $4 \%$ formaldehyde in PBS for 20 min. Following a 10-min wash with 


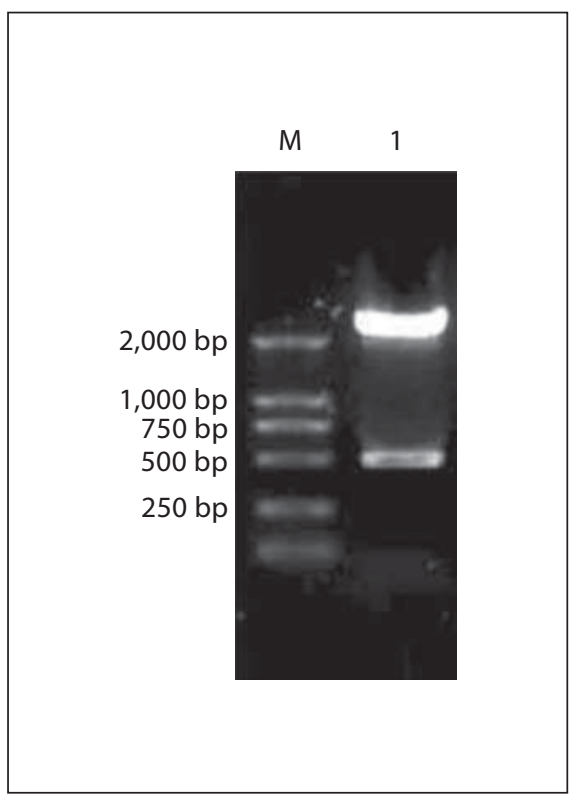

Fig. 1. Identification of recombination vector $\mathrm{pMD}-18 / \mathrm{DEV}$ UL24 by restriction enzymes digestion. Lane $\mathrm{M}=\mathrm{DNA}$ marker; lane 1 = products of PCR $510 \mathrm{bp}$ and of vector pMD-18T 2,700 bp.

PBS containing $50 \mathrm{mM}$ ammonium chloride, the cells were permeabilized with $0.1 \%$ Triton X-100 (v/v in PBS) for $4 \mathrm{~min}$. After detergent treatment, the coverslips were washed in PBS containing $1 \%$ BSA and then blocked in 5\% BSA for $30 \mathrm{~min}$. Cells were then incubated with a 1:200 dilution of the rabbit anti-DEV-UL24 serum (prepared by our laboratory) for $1 \mathrm{~h}$. Following incubation with the primary antibody, the coverslips were washed 3 times in PBS containing $0.2 \%$ Tween-20 and stained with fluorescein isothiocyanate-conjugated secondary antibody (goat anti-rabbit, Sigma Chemical Co.) for $30 \mathrm{~min}$. The coverslips were again washed 3 times and mounted onto glass slides with a drop of mounting medium (PBS containing 50\% glycerol-0.1\% BSA), then analyzed with a Nikon 80 i (Nikon, Japan) fluorescence microscope.

\section{Results}

Cloning and Construction of the pET32a/DEV-UL24

The PCR primers used in this study amplified a 510-bp fragment of UL24 gene from DEV CHv strain. The resultant DNA fragment was inserted into pMD18-T. A positive clone (clone pMD-18/DEV-UL24), which contained a 510-bp insert, was thus identified by restriction enzymes analysis (fig. 1) and direct sequencing (data not shown). The constructed pMD-18/DEV-UL24 was cut with EcoRI and XhoI, and the insert was ligated into
pET32a(+) vector precut with the same enzymes. The resulting pET32a/DEV-UL24 was verified by restriction enzymes analysis (fig. 2).

\section{Expression of the Recombinant Protein}

To obtain a highly expressed level of UL24 protein, we tried optimizing expression conditions by using different temperatures $\left(20,25,30,37^{\circ}\right)$, different IPTG concentrations $(0.0,0.2,0.4,0.7,1.0,1.2 \mathrm{mM})$, and different incubation times $(6,5,4,3,2,1 \mathrm{~h})$. We found that the expression level of synthesized pET32a/DEV-UL24 at $30^{\circ}$ was slightly more than at $25^{\circ}$, and no observable difference was seen between 30 and $37^{\circ}$ (fig. 3a). While incubation time was increased, the expressed protein was increased, too (fig. 3b). The different concentrations of IPTG showed no apparent increase in the expressed protein (fig. 3c). The fusion protein was highly expressed after induction at $30^{\circ}$ with 0.4 mM IPTG. SDS-PAGE of cell lysates followed by scanning with the gel image analysis system (Bio-Rad, USA) revealed a major protein band of the expected 38$\mathrm{kDa}$ size (fig. 4). The fusion protein that had an apparent molecular weight of $20 \mathrm{kDa}$ was expressed by pET32a/ BL21. The expression level of pET32a/DEV-UL24 grown was up to $31.3 \%$ of the total cellular protein [23].

\section{Purification and Yield of the Recombinant Protein}

In the presence of $0.4 \mathrm{mM}$ IPTG, the UL24 partial protein was overexpressed in E. coli and analyzed by SDSPAGE. The stained protein bands on the gel were scanned using a gel image analysis system (Bio-Rad, USA), the intensity of each band was transformed into digital data, and the purities of UL24 partial protein from different purified methods were calculated using the numbers of the protein signal densities. With purification using the Ni-NTA column by imidazole, the purity of UL24 partial protein was up to $91.7 \%$ (fig. 5, lane 2), and the protein yield was about $28.6 \mathrm{mg} / \mathrm{l}$ cell culture (table 1). It indicated that a single Ni-NTA column chromatography was sufficient to separate the UL24 partial protein from those of unwanted bacterial proteins. However, the UL24 partial protein, which was purified using SDS-PAGE (fig. 5, lane 1$)$, was purer $(\geq 97 \%)$ than that of using single $\mathrm{Ni}$ NTA column chromatography. However, protein yield was only about $4.46 \mathrm{mg} / \mathrm{l}$ cell culture.

\section{Immunogenicity of the UL24 Partial Protein}

Western immunoblot analysis with anti-DEV polyclonal IgG indicated a significant expression of UL24 partial protein in E. coli. A single band at the $38-\mathrm{kDa}$ region was obtained with the recombinant plasmid pET32a/ 
Fig. 2. Identification of recombination vector pET32a/DEV-UL24 by restriction enzymes digestion. Lane $\mathrm{M}_{1}=$ DNA marker; lane 1 = recombinant plasmid pET32a/ DEV-UL24 was digested with restriction enzyme EcoR/Xho; lane 2 = recombinant plasmid pET32a/DEV-UL24 was digested with only EcoR; lane 3 = recombinant plasmid pET32a/DEV-UL24 was digested with only Xho; lane $4=$ recombinant plasmid pET32a/DEV-UL24; lane $\mathrm{M}_{2}=\lambda$ DNA was digested with restriction enzyme Hind.
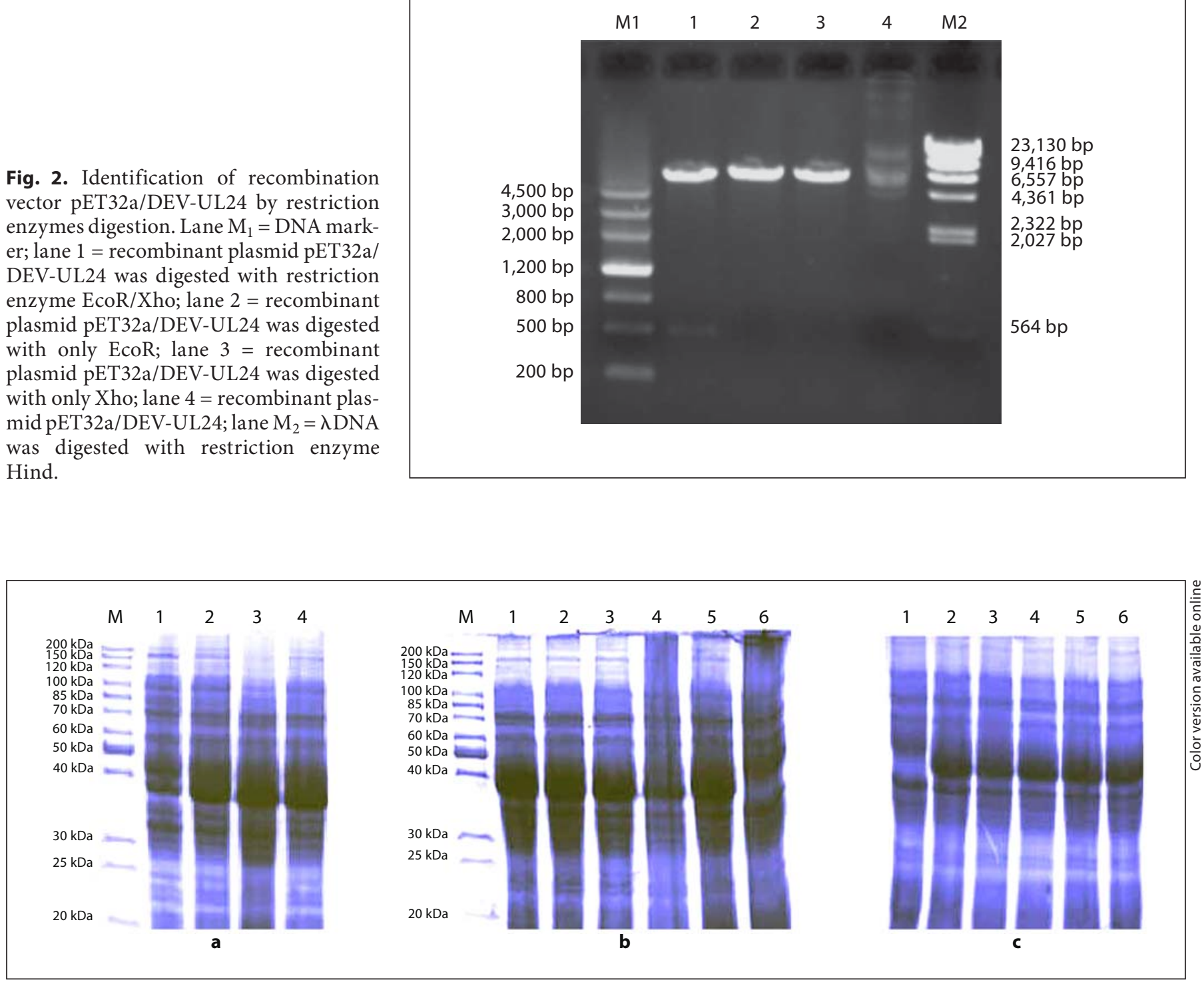

Fig. 3. SDS-PAGE analysis of the expression results of recombinant plasmid pET32a/DEV-UL24 in different conditions. a Effect of temperature of recombinant plasmid pET32a/DEV-UL24 production from BL21 (DE3). Lane $\mathrm{M}=$ Protein marker; lanes 1-4 = cells were grown respectively at $20,25,30,37^{\circ}$ after induction with IPTG. b Time course of recombinant plasmid pET32a/DEV-UL24 production from BL21 (DE3). Lane $\mathrm{M}=$ Protein marker; lanes $1-6=$ cells were grown respectively for $6,5,4,3,2$, and $1 \mathrm{~h}$ after induction with IPTG. c Production of recombinant plasmid pET32a/DEV-UL24 from BL21 (DE3) in different IPTG concentrations. Lanes 1-6 = Cells were grown and induced at 0.0, 0.2, 0.4, $0.7,1.0$, and $1.2 \mathrm{mmol} / \mathrm{l}$ IPTG.
DEV-UL24 in E. coli, which was induced (fig. 6, lane 2) and uninduced (fig. 6, lane 1) by IPTG.

The recombinant protein was observed to be highly immunogenic in ducklings. After the second booster dose, in ducklings the $\mathrm{OD}_{450 \mathrm{~nm}}$ value obtained was 2.50 by ELISA, while unimmunized ducklings showed a
$\mathrm{OD}_{450 \mathrm{~nm}}$ value of 0.43 , and the $\mathrm{OD}_{450 \mathrm{~nm}}$ value of immunized ducklings with DEV commercial attenuated vaccine strain was up to 3.37 (fig. 7). The antibody titers of UL24 partial protein and DEV commercial attenuated vaccine strain both continued to have a high level in ducklings for 98 days. 


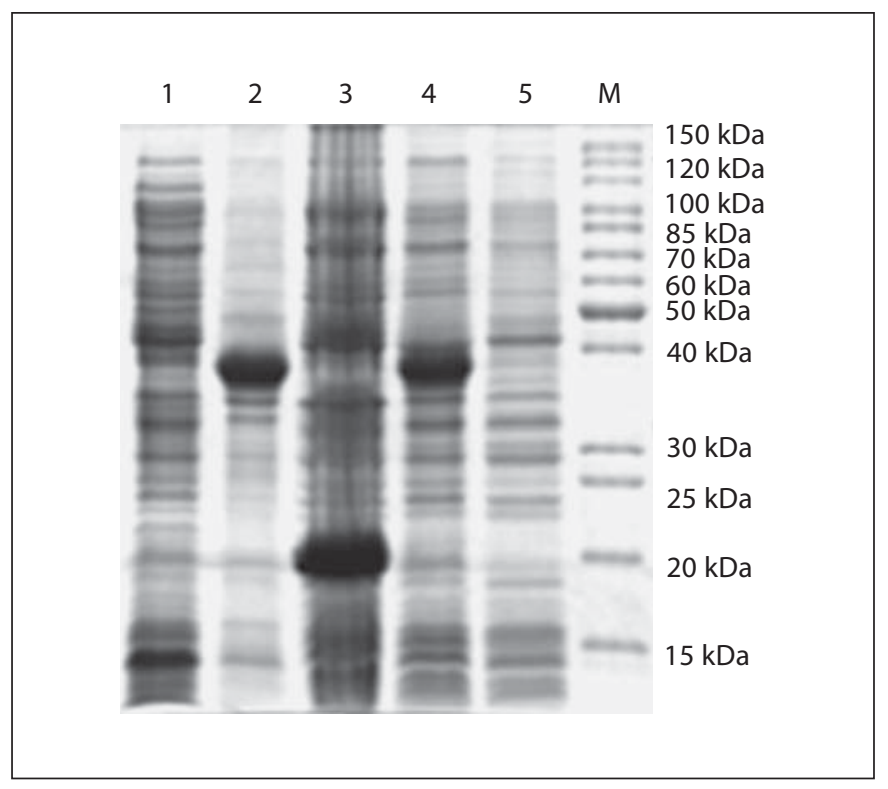

Fig. 4. SDS-PAGE analysis of expression of UL24 protein in E. coli BL21. Lane 1 = Supernatant of pET32a/DEV-UL24/BL21 induced with IPTG at $30^{\circ}$ after centrifuge; lane 2 = sediment of pET32a/ DEV-UL24/BL21 induced with IPTG at $30^{\circ}$ after centrifuge; lane $3=$ total cell lysate of pET32a/BL21 induced with IPTG at $30^{\circ}$; lane 4 = total cell lysate of pET32a/DEV-UL24/BL21 induced with IPTG at $30^{\circ}$; lane $5=$ total cell lysate of pET32a/DEV-UL24/BL21 uninduced at $30^{\circ}$; lane $\mathrm{M}=$ protein molecular weight marker.

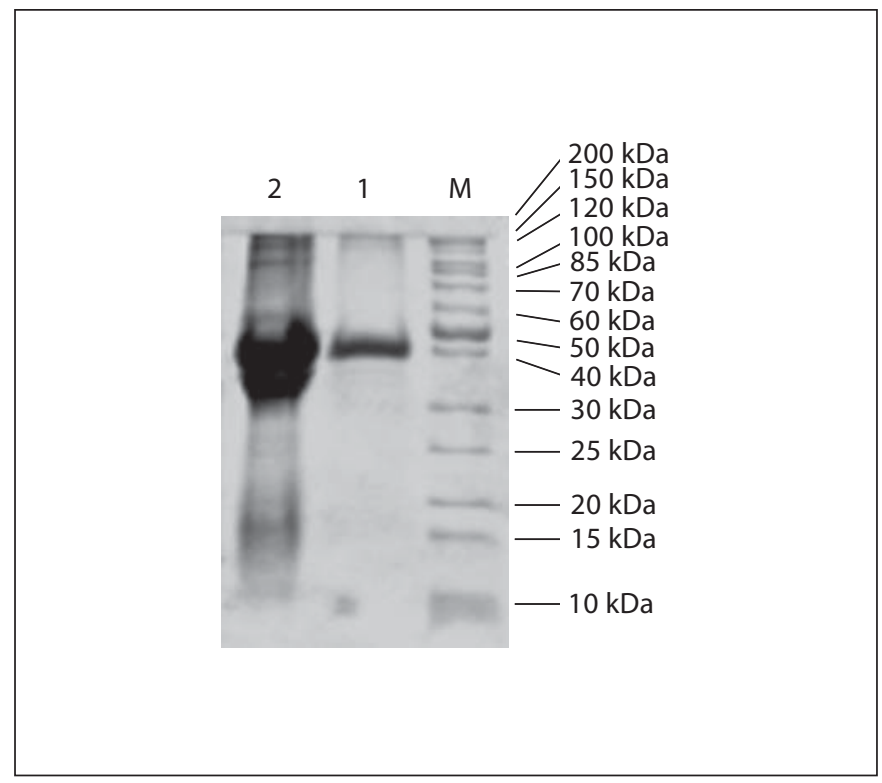

Fig. 5. SDS-PAGE analysis of the purity of recombinant plasmid pET32a/DEV-UL24 from BL21 (DE3). Lane M = Protein marker; lane 1 = recombinant protein from BL21 (DE3) purified by gel electrophoresis; lane 2 = recombinant protein from BL21 (DE3) purified by the $\mathrm{Ni}^{+}$-NTA agarose gel.
Table 1. Yield analysis of recombinant UL24 protein from 1 liter of culture using the $E$. coli expression system

\begin{tabular}{lclcc}
\hline Purification method & $\begin{array}{l}\text { Total protein } \\
\text { mg }\end{array}$ & $\begin{array}{l}\text { UL24 protein } \\
\text { purity }, \%\end{array}$ & $\begin{array}{l}\text { Total UL24 } \\
\text { protein, mg }\end{array}$ & $\begin{array}{c}\text { Protein } \\
\text { yield, \% }\end{array}$ \\
\hline Cell lysate by sonication & 396 & 31.3 & 123.9 & 100 \\
Ni-NTA & 31.2 & 91.7 & 28.6 & 23.1 \\
SDS-PAGE eluate & 4.6 & 97.0 & 4.46 & 3.6 \\
\hline \multicolumn{5}{c}{ a Total protein concentrations were measured by Bradford assay [23]. } \\
b Purity was calculated by quantitation of Coomassie blue-stained SDS-PAGE. \\
\hline
\end{tabular}

\section{Subcellular Location of UL24 Protein}

To confirm the intracellular localization of UL24 protein, indirect immunofluorescence studies were performed with the DEV-UL24 antiserum as described in Materials and Methods. As shown in figure 8b, the UL24 protein appeared in the cytoplasm at $12 \mathrm{~h}$ post infection, and these fluorescent granules became bigger and brighter at $24 \mathrm{~h}$ post infection (fig. $8 \mathrm{c}$ ). Interestingly, at $48 \mathrm{~h}$ post infection the UL24 protein was not diffuse but seemed to be surrounded by specific regions of the nuclear membrane (fig. 8d). These structures were absent in mock-in- fected cells (fig. 8a) and no significant fluorescence was observed with the preimmune serum (not shown). We also knew that these structures would appear and that the ratio of UL24 protein in the perinuclear region would increase at a later time in infection, especially at $48 \mathrm{~h}$ post infection in approximately $80 \%$ of the UL24 protein (fig. 8d). Whether at an earlier or later time in infection, little UL24 protein was observed in the nuclei. It appeared that UL24 protein might localize in nuclear membrane and be expressed at a later stage when cells are infected with DEV. 


\section{Discussion}

In our experiment we have previously attempted to isolate and purify the complete UL24 amino acid sequence as a fusion protein form. Though the sequences of the recombinant plasmids, such as protocaryon expression vectors (pET32a, pET28a and PGEX-4T-1), were correctly confirmed, the protein of interest was not detected on the SDS-PAGE. It seemed that the expression of the gene sequence was unfavorable in E. coli expression systems or cytotoxicity. The UL24 gene of HSV-1 was expressed in insect cells from a recombinant baculovirus [8]. However, as the UL24 gene product of HSV-2 was expressed in a BL21 (DE3) strain of E. coli from a recombinant plasmid pGEX-4T-UL24 [5], there might be a difference between HSV-2 and DEV. Fortunately, the UL24 protein with immunogenicity, in which amino acid peptide is mainly located on the latter 241-410 amino acids of a complete sequence, could be expressed in the protocaryon expression system. Although the fusion expression protein includes a prokaryotic cell protein, thioredoxin, which could not only reduce the digestion by bacterial proteases but also promote the expression of recombinant fusion protein like molecular chaperones [24], the expression yield of DEV UL24 (= 31.3\%) from BL21 seemed lower than that of other genes by optimization of induced conditions.

Here, we showed DEV UL24 partial protein can be efficiently expressed in E. coli. The cells were incubated at $30^{\circ}$ for $6 \mathrm{~h}$ with $0.4 \mathrm{mM}$ IPTG so as to lower the rate of cell growth at a lower temperature and simultaneously the incubation time was increased to $6 \mathrm{~h}$ to increase the cell mass. The rate of protein synthesis is decreased with a slower rate of cell growth and thus sufficient time for proper protein folding is provided, increasing the possibility of the protein to be present in the native form [25]. Compared with different methods of purification, we

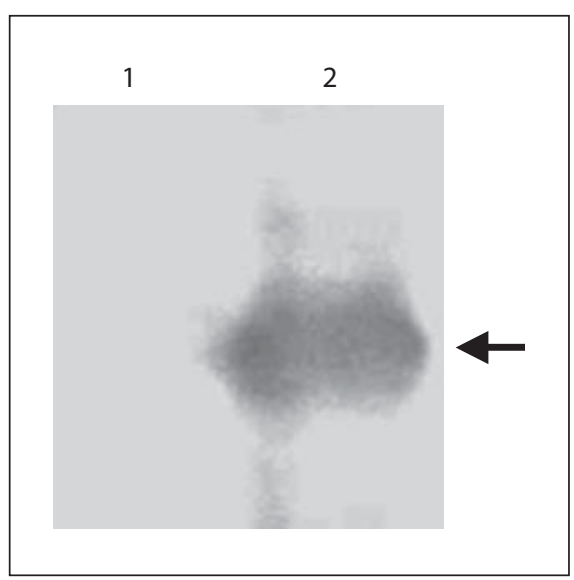

Fig. 6. Western blotting identification of recombinant protein UL24 expressed in E. coli with the rabbit serum of anti-DEV IgG. Lane 1 = Expression of recombinant plasmid pET32a/DEV-UL24 uninduced $E$. coli cell lysate; lane 2 = expression of recombinant plasmid pET32a/DEV-UL24 induced by IPTG.
Fig. 7. Immunogenicity detection of the UL24 protein by ELISA. Purified expression protein was coated and the sera from immunized ducklings with UL24 protein were used as primary antibody, and then incubated with HRP-conjugated goat antiduck IgG secondary antibody. Subsequently, the $\mathrm{OD}_{450 \mathrm{~nm}}$ values were measured after incubation with TMB.

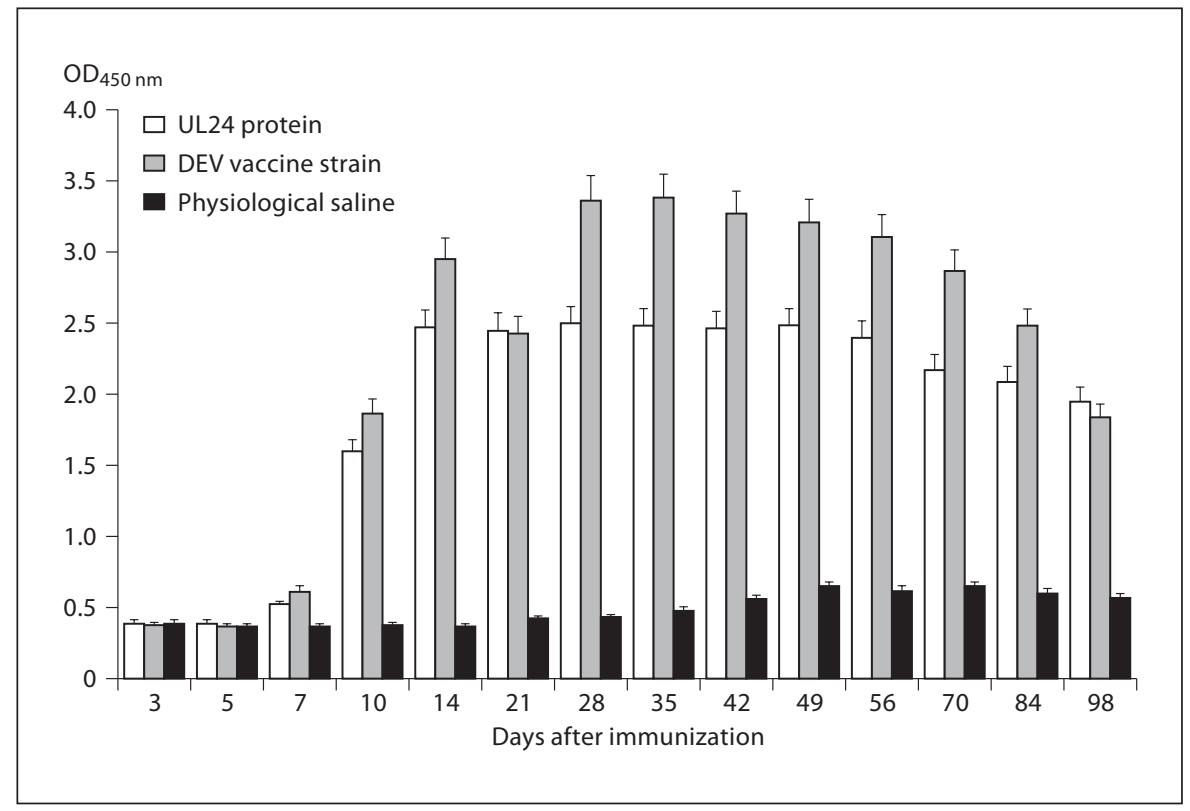


Fig. 8. Intracellular localization of the UL24 protein in DEV-CHv-infected DEFs. Mock- and DEV-CHv-infected cells were fixed at the indicated times post infection and processed for indirect immunofluorescence. Mock-infected cells were fixed after $48 \mathrm{~h}$ incubation (a); DEV-CHv-infected cells were fixed at 12 (b), 24 (c), and $48 \mathrm{~h}$ post infection $(\mathbf{d}) . \times 400$.
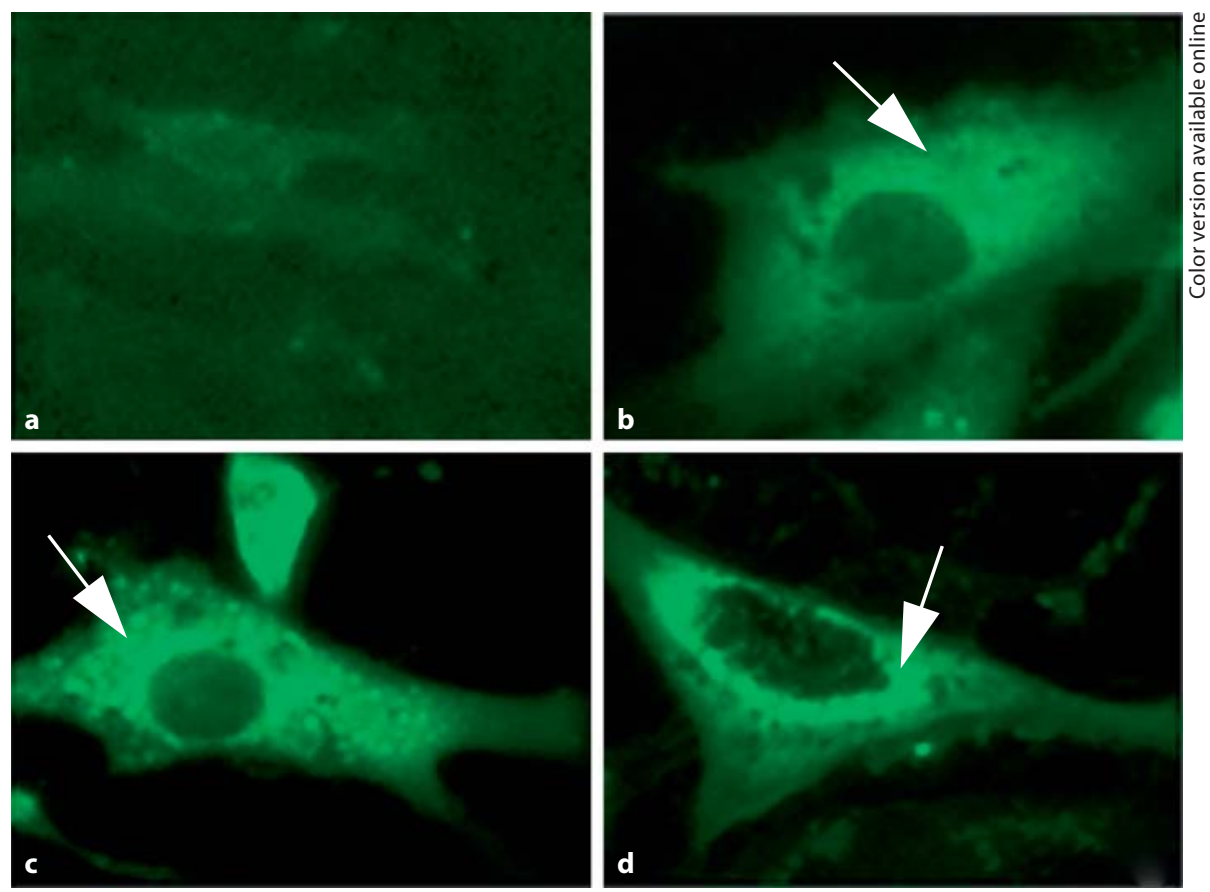

discovered that the affinity chromatography method was the best to purify large quantities of protein from E. coli. Although the purified protein yield using SDS-PAGE was lower than that of the chromatography, the purity of recombinant protein was higher by up to $97 \%$, moreover it was cost-effective, since the UL24 partial protein was expressed in E. coli and purification employed no special instruments or reagents and no toxic components were used in protein preparation. These results, along with the good yield and purity obtained, encourage further studies on the more detailed immunological properties of UL24 protein, such as the ability to induce DEV neutralizing antibodies and the production of anti-UL24 monoclonal antibodies, which together might be useful for the development of new diagnostic methods.

Although it is not known why the expression of UL24 is so complicated [8], antigenicity detection by ELISA showed that unimmunized ducklings had a low titer $\left(\mathrm{OD}_{450 \mathrm{~nm}}=0.42\right)$ against this protein of UL24. On day 10, after primary immunization and one booster, the ELISA titer was 1.60 . On day 28 , it rose to 2.5 (fig. 7). Also, the results of comparison with titers of a DEV commercial attenuated vaccine strain suggested that UL24 partial protein is highly immunogenic. A rabbit antiserum produced against DEV was able to detect this recombinant UL24 partial protein from $E$. coli by Western blot analysis with high avidity. So the rapid immunoassay for detec- tion and quantification of DEV UL24 partial proteinspecific antibodies in immunized hosts would be developed using this recombinant polypeptide. Some of the important attributes of a candidate molecule for vaccine development are that they should be highly conserved among various members of the same species, they should be expressed on the surface of pathogens so that antigenpresenting cells can easily recognize them, and they should be immunogenic [26]. The expressed partial protein of DEV UL24 would therefore serve as a tool to identify its subcellular localization. In immunofluorescence studies of infected cells with our antisera, we observed variable perinuclear and cytoplasmic staining, particularly at later times in infection. UL24 protein might be mostly localized to the nuclear membrane and expressed at a later stage. We know that mutants with lesions in herpes virus UL24 show a reduced ability to replicate in tissue culture [4] and have reduced thymidine kinase activity as the UL24 gene overlaps with thymidine kinase [3]. Thus, like HSV-1 UL24 [8], one possibility is that UL24 is involved in inflow of DEV from the cytoplasmic to nuclear membrane, with participation of viral DNA replication and cellular transport proteins. Although there is no information about DEV UL24 to elucidate this issue, the antiserum described here may help us to gain further knowledge about the relationships between properties and the foundation of UL24 protein. 


\section{Acknowledgments}

The research was supported by the National Natural Science Foundation of China (30771598), New Century Excellent Talents Program in University (NCET-06-0818), Program for Changjiang Scholars and Innovative Research Team in University (IRT0848), the earmarked fund for Modern Agro-Industry Technology Research System (nycytx-45-12), Scientific and Technological Innovation Major Project Funds in University (706050), National Sci- ence and Technology Support Programs (2007Z06-017), the Cultivation Fund of the Key Scientific and Technical Innovation Project, Department of Education of Sichuan Province (07ZZ028), Sichuan Province Outstanding Youths' Fund (03ZQ026029/ 05ZQ026-038/07ZQ026-132), Sichuan Province Research Program (07JY029-016/07JY029-017/07ZA051/2008JO0003/2008JY0100/2008JY0102/2009JY0070) and Program for Key Disciplines Construction of Sichuan Province (SZD0418).

\section{References}

1 Lukasz K, Lisa K, Nick V, Rychlewski L, Ginalski K: Human herpesvirus 1 UL24 gene encodes a potential PD-(D/E) XK endonuclease. J Virol 2006;80:2575-2577.

$\checkmark 2$ Davison AJ: Herpesvirus genes. Rev Med Virol 1993;3:237-244.

3 Blakeney S, Kowalski J, Tummolo D, DeStefano J, Cooper D, Guo M, Gangolli S, Long D, Zamb T, Natuk RJ, Visalli RJ: Herpes simplex virus type 2 UL24 gene is a virulence determinant in murine and guinea pig disease models. J Virol 2005;79:10498-10506.

$\checkmark 4$ Jacobson JG, Martin SL, Coen DM: A conserved open reading frame that overlaps the herpes simplex virus thymidine kinase gene is important for viral growth in cell culture. J Virol 1989;63:1839-1843.

$\checkmark 5$ Hong-Yan Z, Murata T, Goshima F, Takakuwa H, Koshizuka T, Yamauchi Y, Nishiyama Y: Identification and characterization of the UL24 gene product of herpes simplex virus type 2. Virus Genes 2001;22:321-327.

6 Jacobson JG, Chen SH, Cook WJ, Kramer MF, Coen DM: Importance of the herpes simplex virus UL24 gene for productive ganglionic infection in mice. Virology 1998;242: 161-169.

7 Gompels UA, Nicholas J, Lawrence G, Jones M, Thomson BJ, Martin ME, Efstathiou S, Craxton M, Macaulay HA: The DNA sequence of human herpesvirus-6: structure, coding content, and genome evolution. Virology 1995;209:29-51.

$\checkmark 8$ Pearson A, Coen DM: Identification, localization, and regulation of expression of the UL24 protein of herpes simplex virus type 1 . J Virol 2002;76:10821-10828.
9 Whitbeck JC, Lawrence WC, Bello LJ: Characterization of the bovine herpesvirus 1 homolog of the herpes simplex virus 1 UL24 open reading frame. Virology 1994;200:263270.

10 Tognon M, Guandalini R, Romanelli MG, Manservigi R, Trevisani B: Phenotypic and genotypic characterization of locus Syn 5 in herpes simplex virus 1. Virus Res 1991;18: 135-150.

11 Ward PL, Roizman B: Herpes simplex genes: the blueprint of a successful human pathogen. Trends Genet 1994;10:267-274.

12 Toth TE: Active immunization of white pekin ducks against duck virus enteritis duck plague with modified live virus vaccines immunization of ducklings. Am J Vet Res 1970; 31:1275-1279.

13 Proctor SJ: Pathogenesis of duck plague in the bursa of fabricius thymus and spleen. Am J Vet Res 1976;37:427-431.

14 Rajan A, Nair MK, Maryamma KI, Valsala KV: Studies on the epidemiology symptoms and pathoanatomy of duck plague infection duck viral enteritis. Indian Vet J 1980;57:1215.

15 Das NP, Dewan ML, Baki MA, Das PM, Sarker AJ: Pathology of experimental duck plague in Bangladesh. Indian Vet J 1990;67: 197-202.

16 Marlier D, Jaumin F, Delleur V, Sturbois M, Vindevogel H: Duck plague: a permanent threat for domestic and wild anatids. Ann Med Vet 2001;145:287-291.

17 Malmarugan S, Sulochana S: Detection of duck plague viral antigen in tissues by immunoperoxidase test. Indian Vet J 2002;79: 103-105.

-18 Kolaskar AS, Tongaonkar PC: A semi-empirical method for prediction of antigenic determinants on protein antigens. FEBS Lett 1990;276:172-174.
19 Sambrook J, Fritsch EF, Maniatis T: Molecular Cloning: A Laboratory Manual. Cold Spring Harbor/NY, Cold Spring Harbor Laboratory Press, 1989.

20 Lee P, Colman RF: Expression, purification, and characterization of stable, recombinant human adenylosuccinate lyase. Protein Expr Purif 2007;51:227-234.

21 Sun Z, Lu W, Tang Y, Zhang J, Chen J, Deng H, Li X, Liu JN: Expression, purification and characterization of human urodilatin in $E$. coli. Protein Expr Purif 2007;55:312-318.

$\checkmark 22$ Towbin H, Staehelin T, Gordon J: Electrophoretic transfer of proteins from polyacrylamide gels to nitrocellulose sheets: procedure and some applications. Proc Natl Acad Sci USA 1979;76:4350-4354.

23 Bradford MM: A rapid and sensitive method for the quantitation of microgram quantities of protein utilizing the principle of proteindye binding. Analyt Biochem 1976;72:248254.

24 Yang J, Zhang W, Liu K, Jing S, Guo G, Luo P, Zou Q: Expression, purification, and characterization of recombinant human interleukin 24 in Escherichia coli. Protein Expr Purif 2007;53:339-345.

25 Kothari H, Kumar P, Singh N: Prokaryotic expression, purification, and polyclonal antibody production against a novel drug resistance gene of Leishmania donovani clinical isolate. Protein Expr Purif 2006;45:15-21.

26 Khushiramani R, Girisha SK, Karunasagar I, Karunasagar I: Cloning and expression of an outer membrane protein ompTS of Aeromonas hydrophila and study of immunogenicity in fish. Protein Expr Purif 2007;51:303-307. 